\title{
Cost-effectiveness analysis of pneumococcal conjugate vaccine 13 -valent in older adults in Colombia
}

\author{
Jaime E Ordóñez ${ }^{*}$ and John J Orozco ${ }^{2}$
}

\begin{abstract}
Background: Nowadays, there are two vaccination strategies in Colombia to prevent pneumococcal diseases in people over 50 years. Our aim is to estimate cost-effectiveness of pneumococcal conjugate vaccine 13-valent (PCV13) versus pneumococcal polysaccharide vaccine 23-valent (PPSV23) to prevent pneumococcal diseases and their related mortality in people over 50 years old in Colombia.

Methods: A Markov model was developed with national data, including pneumococcal serotypes distribution in Colombia between 2005 and 2010. Vaccination of a cohort was simulated and a five year time horizon was assumed. Analysis was done from a perspective of a third party payer. Direct costs were provided by a national insurance company; sensitive univariate and probabilistic analysis were done for epidemiological and clinical effectiveness parameters and costs.

Results: PCV13 avoids 3560 deaths by pneumococcal infections versus PPSV23 and 4255 deaths versus no vaccine. PCV13 prevents 79633 cases by all-cause pneumonia versus PPSV23 and 81468 cases versus no vaccine. Total costs (healthcare and vaccines costs) with PCV13 would be U.S. \$ 97,587,113 cheaper than PPSV23 and it would save U.S. \$ $145,196,578$ versus no vaccine.

Conclusion: PCV13 would be a cost-saving strategy in the context of a mass vaccination program in Colombia to people over 50 years old because it would reduce burden of disease and specific mortality by pneumococcal diseases, besides, it saves money versus PPSV23.
\end{abstract}

Keywords: Streptococcus pneumoniae, Pneumococcal vaccines, Health economics, Middle aged, Aged, Colombia

\section{Background}

Streptococcus pneumoniae (pneumococcus) is a frequent cause of serious infectious diseases in children and adults. Pneumococcal infections may be invasive such as sepsis and meningitis [Invasive Pneumococcal Disease (IPD)], or non-invasive, such as pneumonia, the most common form of serious pneumococcal disease in adults [1]. According to the World Health Organization (WHO), in 2000 there were about 14.5 million cases of pneumococcal disease (invasive and noninvasive) [2].

Pneumococcal pneumonia is the most common bacterial cause of community acquired pneumonia (CAP) in adults [3]. Mortality rates for pneumococcal CAP are

\footnotetext{
* Correspondence: gerencia@hemogroup.com.co

'HEMO Group, Carrera 25 A \# 1 A Sur-45, piso 5. Medellín, Colombia

Full list of author information is available at the end of the article
}

between $10 \%$ and $30 \%$ in adults and have remained constant over the past four decades [4-8].

Increased bacterial resistance [9], an increase in the prevalence of immunocompromised people, especially by HIV, immunosuppressive therapy in oncology, and transplantation medicine; as well, the increase in life expectancy that is accompanied by immune senescence processes likely contribute to sustained morbidity and mortality impact of this disease $[10,11]$.

Given the burden of disease by pneumococcal diseases in worldwide, a prevention strategy with vaccination may be the most cost-effective approach to health systems. This is not a new topic, there are randomized clinical trials (RCTs) from 1940s [12,13], but it was just until 1977 that began the widespread use of this technology, when pneumococcal polysaccharide 14-valent vaccine (PPSV14)
C Biomed Central

(c) 2014 Ordóñez and Orozco; licensee BioMed Central Ltd. This is an Open Access article distributed under the terms of the Creative Commons Attribution License (http://creativecommons.org/licenses/by/2.0), which permits unrestricted use, distribution, and reproduction in any medium, provided the original work is properly credited. 
was authorized and later, in 1983, PPSV23 was launched. The latter is a vaccine made with 23 different capsular polysaccharide serotypes and has been indicated to prevent pneumococcal disease in children over two years old with risk factors and adults over 50 years old. International clinical guidelines generally recommend its use in adults over 65 years old, and for people under 65 years old, who have chronic comorbidities that put them at higher risk of disease [14].

In 2000, a pneumococcal vaccine with a different technology was launched, which conjugates pneumococcal serotypes with a diphtheria protein (CRM197). This one was the pneumococcal conjugate vaccine 7-valent (PCV7) that demonstrated its effectiveness [15-17] to prevent IPD, pneumonia and acute otitis media (AOM) caused by vaccine serotypes in children aged between 2 months and 9 years old. It has also been studied in adults, including patients with HIV [18]. Later, in 2006, a WHO expert group established that future pneumococcal conjugate vaccines may be evaluated on the basis of immunogenicity studies, such that efficacy studies with disease outcomes would not be necessary for regulatory approval. This statement was based on the PCV7 and PCV9 RCTs, that found an association between an antibody concentration $>0.35 \mathrm{mcg} / \mathrm{ml}$ of the serotypes contained in these vaccines and prevention of IPD by the respective serotype [19].

In 2010, a 13-valent pneumococcal conjugate vaccine (PCV13) was approved for prevention of IPD, pneumonia and AOM caused by serotypes included in the vaccine in children between 2 months and 5 years old. Later, in 2011, PCV13 was approved to use in people over 50 years to prevent pneumococcal diseases (IPD and pneumonia) caused by serotypes $13,4,5,6 \mathrm{~A}, 6 \mathrm{~B}, 7 \mathrm{~F}, 9 \mathrm{~V}, 14,18 \mathrm{C}$, 19A, $19 \mathrm{~F}$ and $23 \mathrm{~F}$.

Given that there are two technologies for prevention of pneumococcal diseases in people over 50 years old, the 23-valent polysaccharide vaccine and the 13-valent conjugate vaccine, the aim of this study was to estimate incremental cost-effectiveness ratio (ICER) of PCV13 versus PPSV23 and versus no vaccine in people over 50 years old in Colombia.

\section{Methods \\ Model}

A cost-effectiveness analysis was performed using a Markov model with a first-order microsimulation to determine the risk of developing IPD and pneumonia in people over 50 years; the original model was developed by PAI (Policy Analysis Inc.) to Pfizer. The model simulates cohorts of individuals which represent the age and risk profile of the populations. Each individual's risk was adjusted based on age and risk profile of individuals according to their medical history, such as chronic diseases or immunocompromised illnesses. No previous vaccination with PPSV23 was assumed. The model assumed that at the beginning, individuals would be vaccinated with PCV13 or PPSV 23 or would not be vaccinated. Over the course of the simulations, individuals were at risk for four clinical outcomes: sepsis, meningitis, inpatient pneumonia and outpatient pneumonia. Mortality rates from IPD and pneumonia were considered to calculate deaths avoided. Risk reduction associated with the vaccines relied on the clinical presentation of diseases: IPD, inpatient pneumonia or outpatient pneumonia; as well as the vaccine, time since vaccination, age at time of diseases, and risk profile [20] (Figure 1) Further methodologic details can be referenced from application of the model to the US setting [20].

Costs of medical treatments were calculated based on the site of healthcare (inpatient or outpatient), age of patients, and their risk profile. To determine epidemiologic distribution of $S$. pneumoniae serotypes, we used the data of Regional Vaccine System (SIREVA II, by their acronym in Spanish), which reports serotypes of all isolates made in Colombia by IPD. For this purpose, we took the distribution of S. pneumoniae serotypes found in Colombia between 2005 and 2010 in people older than 50 years [21]. The model was calculated using a discount rate of $3 \%$ for both costs and effects, according to WHO recommendations [22].

Analysis was done from the perspective of a third-party payer in Colombia. Three alternatives were considered: no vaccination, vaccination with PCV13 or vaccination with PPSV23. The model horizon was five years and we assumed vaccination coverage of $70 \%$. An incremental cost-effectiveness analysis was made among these three strategies in terms of avoiding cases and deaths for each disease and life-years gained (LYG).

The data used in this study are referenced in each item and are publically available in medical databases and official reports of Colombia, except hospitalization costs, which were provided by SURA, a national health insurance.

\section{Demographic and epidemiological parameters}

The vaccinated cohort was calculated based on official data from a projection of population over 50 years in Colombia in 2012 (Table 1) [23]. The proportion of people in each age group with low, medium, or high risk for pneumococcal diseases or related complications was based on a study of pneumococcal disease burden in older adults in the United States (Table 2) [24]. The risk groups were classified as follows [25]:

- Low risk: immunocompetent people without chronic diseases.

- Medium risk: immunocompetent people with chronic diseases, such as cardiovascular, hepatic, lung illnesses or diabetes. 


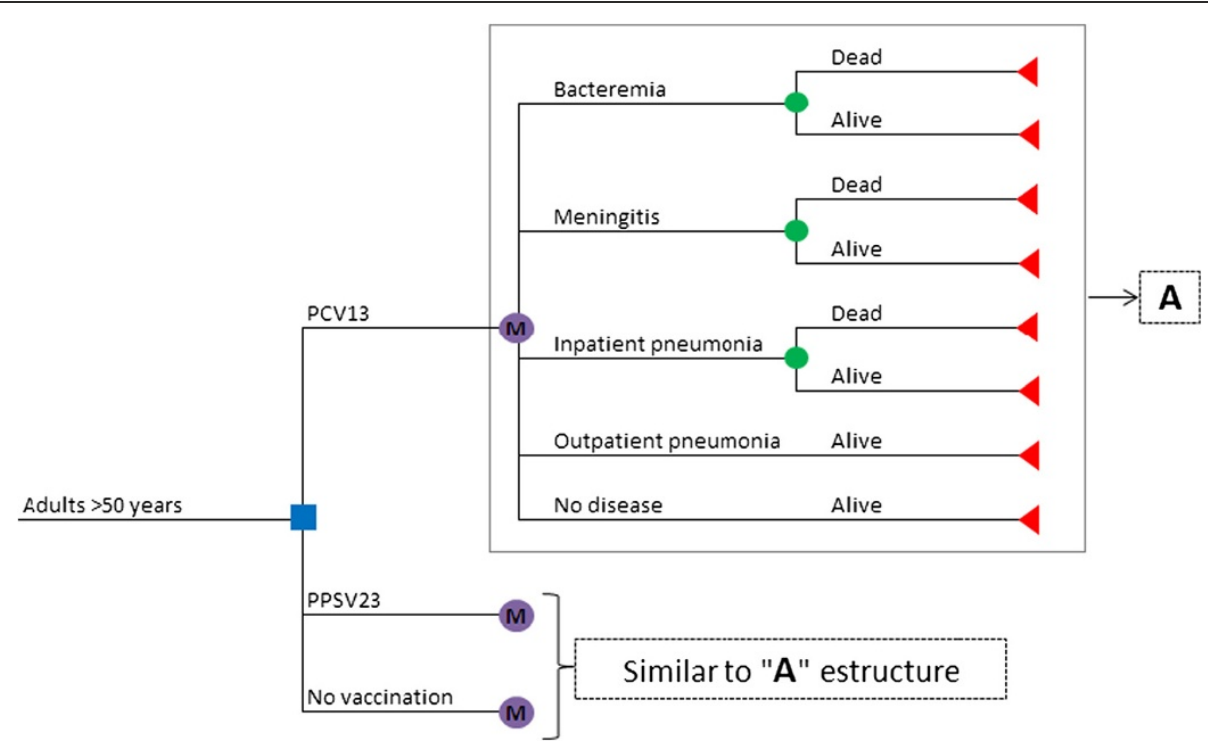

Figure 1 Markov microsimulation model of pneumococcal diseases to determine the cost-effectiveness of vaccination with PCV13, PPSV23 or not vaccine, in people older than 50 years in Colombia.

- High risk: immunocompromised people as a result of splenic dysfunction, malignancies, HIV, organ transplant or chronic renal failure.

The model assumed that high-risk people who were vaccinated with PPSV23 will be revaccinated five years later [26].

We calculated the likelihood of falling ill with IPD, inpatient pneumonia or outpatient pneumonia based on two age groups of 50-64 years, and $>65$ years. No literature that would identify the specific risk for additional age groups was found (Table 1) [27-30]. Mortality by IPD and pneumonia was calculated according to official data of general mortality by age groups in Colombia [31] and it was adjusted based on Koivula et al. [32].

Pneumococcal serotype distribution in adults older than 60 years between 2005 and 2010 in Colombia was based on reports of SIREVA II. Thus, proportion of S. pneumoniae serotypes circulating in Colombia covered by each vaccine was calculated, as well: PCV13 covers $64.6 \%$ and PPSV23 covers $76.9 \%$ [21].

\section{Vaccine effectiveness}

IPD

Parameters of effectiveness of initial vaccination with PPSV23 in immunocompetent adults over 50 years and immunocompromised adults over 65 years were adapted from the approach by Smith et al., and it was adjusted for age, risk group, and time since vaccination [33]. As these data were taken from a panel of experts through Delphi methodology, sensitivity analysis and probabilistiva analysis were done [34], and these have been consistent with former results in the United Kingdom [35]. Effectiveness of initial vaccination with PPSV23 in immunocompromised adults between 50 and 64 years old in the year after vaccination was based on data from Shapiro et al. [34]. In the same way, we assumed a rate of decline in protection after vaccination [10]. It was assumed that the effectiveness of revaccination with PPSV23 was $75 \%$ of initial value (Table 3 ).

Effectiveness of PCV13 for people over 50 years in the groups of low and moderate risk in the year after vaccination, was adapted from the effectiveness of PCV7 for children $[15,35,36]$, assuming similar effectiveness against the six pneumococcal serotypes not included in PCV7. It was assumed a conjugate vaccine would have similar effectiveness as in children, but that this effectiveness would decline with increasing age after 50 due to immunesenescence. The decline in PCV13 effectiveness with age in people over 50 years was assumed as $50 \%$ of the corresponding rate of decline for PPSV23. Further for people in high-risk group, it was assumed PCV13 would have $78 \%$ of the corresponding age-specific effectiveness of adults with low and moderate risk [37]. It was assumed that effectiveness of both vaccines was constant across each of the serotypes contained in each vaccine, according to WHO recommendation of non-inferiority in the proportion of vaccine serotypes with antibody levels $>0.35 \mathrm{mcg} / \mathrm{ml}[38,39]$ (Table 3).

\section{All cause-pneumonia}

An effectiveness of zero (0) for PPSV23 against all-cause pneumonia was assumed; based on several studies that also have served as information source in other economic 
Table 1 Demographic and epidemiological parameters on the likelihood of developing pneumococcal diseases in people over 50 years in Colombia, 2012

\begin{tabular}{|c|c|c|c|}
\hline Parameter & Mean value & Data distribution & Reference \\
\hline \multicolumn{2}{|l|}{ Population distribution } & \multirow[t]{5}{*}{ No variation } & \multirow[t]{5}{*}[31]{} \\
\hline $50-64$ years & $5^{\prime} 963,690$ & & \\
\hline $65-74$ years & $1^{\prime} 987,534$ & & \\
\hline $75-79$ years & 641,029 & & \\
\hline $80-99$ years & 630,983 & & \\
\hline Discount rate & $3 \%$ & No variation & Assumption \\
\hline Vaccination coverage & $70 \%$ & Beta & Assumption \\
\hline \multicolumn{4}{|c|}{ Epidemiological parameters: } \\
\hline \multicolumn{2}{|c|}{ Incidence of bacteremia: } & \multirow[t]{3}{*}{ Beta } & \multirow[t]{3}{*}[24]{} \\
\hline $50-64$ years & $0.0667 \%$ & & \\
\hline$\geq 65$ years & $0.181 \%$ & & \\
\hline \multicolumn{2}{|c|}{ Incidence of meningitis: } & \multirow[t]{3}{*}{ Beta } & \multirow[t]{3}{*}[24,25]{} \\
\hline $50-64$ years & $0.0046 \%$ & & \\
\hline$\geq 65$ years & $0.0114 \%$ & & \\
\hline \multicolumn{2}{|c|}{ Incidence of all-cause pneumonia: } & \multirow[t]{3}{*}{ Beta } & \multirow[t]{3}{*}[24,25]{} \\
\hline $50-64$ years & $0.3281 \%$ & & \\
\hline$\geq 65$ years & $2.1627 \%$ & & \\
\hline \multicolumn{2}{|l|}{ Bacteremia mortality: } & \multirow[t]{5}{*}{ Beta } & \multirow[t]{5}{*}[23,31]{} \\
\hline $50-64$ years & $3.5 \%$ & & \\
\hline $65-74$ years & $5.7 \%$ & & \\
\hline $75-84$ years & $11.4 \%$ & & \\
\hline $85-99$ years & $27.5 \%$ & & \\
\hline \multicolumn{2}{|l|}{ Meningitis mortality: } & \multirow[t]{5}{*}{ Beta } & \multirow[t]{5}{*}[23,31]{} \\
\hline $50-64$ years & $26.7 \%$ & & \\
\hline $65-74$ years & $19.5 \%$ & & \\
\hline $75-84$ years & $37.4 \%$ & & \\
\hline $85-99$ years & $40.0 \%$ & & \\
\hline \multicolumn{2}{|c|}{ Inpatient pneumonia mortality: } & \multirow[t]{5}{*}{ Beta } & \multirow[t]{5}{*}[23,31]{} \\
\hline $50-64$ years & $0.9 \%$ & & \\
\hline $65-74$ years & $2.9 \%$ & & \\
\hline $75-84$ years & $6.2 \%$ & & \\
\hline $85-99$ years & $14.6 \%$ & & \\
\hline \multicolumn{4}{|l|}{ Costs (U.S. \$) } \\
\hline Inpatient pneumonia & Mean (SD) & & \\
\hline $50-64$ years & $1,765(4,005)$ & \multirow[t]{4}{*}{ Gamma } & \multirow{4}{*}{$\begin{array}{l}\text { Sura EPS } \\
\text { (local data) }\end{array}$} \\
\hline $65-74$ years & $1,932(4,721)$ & & \\
\hline $75-79$ years & $2,688(12,332)$ & & \\
\hline $80-99$ years & $1,309(3,355)$ & & \\
\hline Bacteremia & & & \\
\hline $50-64$ years & $10,434(16,835)$ & Gamma & Sura EPS \\
\hline $65-74$ years & $8,495(10,782)$ & & \\
\hline $75-79$ years & $6,753(10,380)$ & & \\
\hline $80-99$ years & $4,849(9,772)$ & & \\
\hline
\end{tabular}

Table 1 Demographic and epidemiological parameters on the likelihood of developing pneumococcal diseases in people over 50 years in Colombia, 2012 (Continued)

\begin{tabular}{llll}
\hline Meningitis & & \\
\hline $50-64$ years & $7,789(8,114)$ & Gamma & $\begin{array}{l}\text { Sura EPS } \\
\text { (local data) }\end{array}$ \\
\cline { 1 - 1 } $65-74$ years & $7,783(8,025)$ & & \\
\cline { 1 - 2 } $75-79$ years & $7,783(8,025)$ & & \\
\cline { 1 - 2 } $80-99$ years & $7,783(8,025)$ & & \\
\hline
\end{tabular}

assessments [40-45]. For PCV13, effectiveness observed in children with radiological-confirmed pneumonia was assumed in inpatient pneumonia and it was adjusted for the effect of immune-senescence following a similar procedure as described with IPD [10]. For outpatient pneumonia, the starting point for effectiveness estimation was $6 \%$, based on the percent reduction in children with pneumonia without radiological confirmation [11]. We assumed the same decline rate of effectiveness adjusted by age, used in patients over 50 years with IPD. In immunocompromised patients, it was assumed a PCV13 effectiveness of $65 \%$ less than immunocompetent adults of the same age, based on data of Klugman et al. [37] (Table 3).

\section{Economic parameters}

Vaccine costs were taken from the Pan American Health Organization Revolving Fund prices; which lists values of different vaccines for the Americas in 2013; cost per dose of PCV13 is U.S. \$ 15.84 and cost per dose of PPSV23 is U.S. \$ 6.60 [46]. For administration cost for application of either vaccine, we assumed a value of U.S. $\$ 1$. To calculate these values in American dollars, we assumed a value of \$COP 1800 per U.S. \$ 1 [47].

To determine the costs of treatment of sepsis, meningitis and pneumonia in adults over 50 years in Colombia, we took the information from a health insurance company with national presence and over 1.8 million members, which ensures the representativeness of Colombian population. Costs were determined based on the value actually paid by insurance companies to different hospitals and includes all services rendered during the stay including visits-hospital, diagnostic aids, antibiotics and other treatments necessary for recovery until discharge.

Table 2 Distribution of people in each age group, with low, medium or high risk for pneumococcal diseases or their complications [21]

\begin{tabular}{lccc}
\hline Age groups & \multicolumn{3}{c}{ Risk level } \\
\cline { 2 - 4 } & Low & Medium & High \\
\hline $50-64$ years & $52.2 \%$ & $36.6 \%$ & $11.2 \%$ \\
\hline $65-74$ years & $41.7 \%$ & $38.5 \%$ & $19.8 \%$ \\
\hline $75-84$ years & $37.4 \%$ & $36.9 \%$ & $25.7 \%$ \\
\hline $85-99$ years & $36.6 \%$ & $34.3 \%$ & $29.1 \%$ \\
\hline
\end{tabular}


Table 3 PCV13 and PPSV23 effectiveness to prevent IPD in inpatient and outpatient pneumonia in adults over 50 years not previously vaccinated in the first year after vaccination

\begin{tabular}{|c|c|c|c|c|c|c|}
\hline \multirow{2}{*}{$\begin{array}{l}\text { Age groups } \\
\text { (years) }\end{array}$} & \multicolumn{3}{|c|}{ PCV13 } & \multicolumn{3}{|c|}{ PPSV23 } \\
\hline & $\begin{array}{c}\text { IPD } \\
{[14,33,34]}\end{array}$ & $\begin{array}{c}\text { Inpatient } \\
\text { pneumonia [28] }\end{array}$ & $\begin{array}{c}\text { Outpatient } \\
\text { pneumonia [10] }\end{array}$ & $\begin{array}{c}\text { IPD } \\
{[26,27,31,32]}\end{array}$ & $\begin{array}{c}\text { Inpatient } \\
\text { pneumonia [37-42] }\end{array}$ & $\begin{array}{c}\text { Outpatient } \\
\text { pneumonia [37-42] }\end{array}$ \\
\hline $50-64$ & $88.9 \%$ & $24.2 \%$ & $5.6 \%$ & $79.2 \%$ & $0.0 \%$ & $0.0 \%$ \\
\hline $65-74$ & $81.5 \%$ & $21.9 \%$ & $5.1 \%$ & $61.6 \%$ & $0.0 \%$ & $0.0 \%$ \\
\hline $75-79$ & $75.7 \%$ & $20.2 \%$ & $4.7 \%$ & $50.4 \%$ & $0.0 \%$ & $0.0 \%$ \\
\hline $80-99$ & $70.3 \%$ & $18.7 \%$ & $4.3 \%$ & $42.1 \%$ & $0.0 \%$ & $0.0 \%$ \\
\hline
\end{tabular}

IPD: Invasive Pneumococcal Disease.

These costs are based on national tariff manuals. In 2012, this insurance company reported a total of 48 cases of meningitis, 1526 cases of pneumonia and 389 cases of sepsis. These costs were validated with data from a study in three hospitals in Bogota, Colombia, for a period of 18 months in 2011 [48]. The values were adjusted at $3.73 \%$, which was the Consumer Price Index for 2011 reported by National Administrative Department of Statistics of Colombia (DANE by their acronym in Spanish) [23].

\section{Sensitivity analysis}

Probabilistic and univariate sensitivity analyses were made for epidemiological parameters, effectiveness of interventions, and costs included in the model. The parameters that generated a higher level of uncertainty were identified and variance reported. For probabilistic sensitivity analysis a Monte Carlo simulation with a thousand iterations was performed, in order to evaluate each expected value in the distribution of costs and diseases likelihood for each strategy. In the base case, the probabilistic sensitivity analysis report both there were 7,5000,000 simulations and 1,000 trials.

We assumed a gamma distribution for medical costs avoided and the costs of vaccines, considering the kurtosis thereof. Alpha and beta parameters were calculated from standard deviations of the actual data. Results of Monte Carlo simulation show robustness of the model. A univariate sensitivity analysis was made with minimum and maximum values, with the aim to observe the sensitivity of ICER to change in the parameters of each variable.

\section{Cost-effectiveness analysis}

A cost-effectiveness analysis was made to calculate the ICER of vaccines and number of avoided cases in relation to the four conditions of interest: sepsis, meningitis, inpatient pneumonia, and outpatient pneumonia. The calculation was made considering in numerator the costs difference of both alternatives and in denominator their effectiveness difference. Costs were result of the value of one dose of PCV13 or PPSV23, as well as the lower cost incurred on medical treatment for least number of cases of each disease.
Cost-effectiveness analysis of vaccines in relation to specific mortality from sepsis, meningitis and pneumonia and mortality added were made also. Finally, a costeffectiveness analysis was made in relation to the LYG for each strategy.

\section{Results}

Compared to no vaccination, use of PCV13 in adults over 50 is expected to prevent 49857 cases of pneumococcal bacteremia; 3135 of pneumococcal meningitis; 496795 of inpatient pneumonia, 866189 of outpatient pneumonia; and 33980 deaths from pneumococcal infections, over 5 years. Moreover, total costs with the not vaccinating strategy were U.S. \$ 145,196,578 greater than vaccinating with PCV13 (Table 4).

Both vaccination strategies would prevent more deaths and IPD that no vaccination and PCV13 would reduce more than PPSV23. A mass vaccination program in Colombia for adults over 50 years with PCV13 would avoid 79633 additional cases of pneumonia, both inpatient and outpatient, to those prevented with PPSV23. Furthermore, PCV13 would prevent and additional 5127 cases of IPD and 3560 deaths by pneumococcal infections, more than PPSV23 (Table 4).

Total costs (medical costs and vaccination) were highest with the strategy of not vaccinating, and both PPSV23 and PCV13 were cost saving compared with no vaccination. However, vaccination with PCV13 saves U.S. \$ 97 million versus PPSV23 (Table 4).

\section{Cost-effectiveness analysis}

PCV13 is dominant over PPSV23 in terms of mortality avoided and LYG in adults over 50 years, because PCV13 avoids more deaths, generates more LYG, and healthcare costs expected would be lower than PPSV23. ICER indicates that PCV13 would be dominant over PPSV23, both in terms of illness and deaths averted by pneumococcal disease as well as LYG (Table 4).

\section{Sensitivity analysis}

PCV13 would prevent $52.0 \%$ of the cases of pneumococcal bacteremia and meningitis and $12.6 \%$ of all-causes 
Table 4 Cases and direct costs by pneumococcal infections vaccinating with PCV13, PPSV23, or not vaccine in people over 50 years in Colombia

\begin{tabular}{lccccc}
\hline Parameters & PCV13 & PPSV23 & No vaccination (NV) & PCV13-PPSV23 & PCV13-NV \\
\hline Number of cases & & & & & \\
\hline Bacteremia & 34934 & 39809 & 49857 & $-4875(-12.2 \%)$ & $-14923(-29.9 \%)$ \\
\hline Meningitis & 2306 & 2557 & 3135 & $-252(-9.8 \%)$ & $-830(-26.5 \%)$ \\
\hline Inpatient pneumonia & 439971 & 496752 & 496795 & $-56781(-11.4 \%)$ & $-56824(-11.4 \%)$ \\
\hline Outpatient pneumonia & 841546 & 864397 & 866189 & $-22852(-2.6 \%)$ & $-24644(-2.8 \%)$ \\
\hline Deaths by pneumococcal infections & 29726 & 33285 & 33980 & $-3560(-10.7 \%)$ & $-4255(-12.5 \%)$ \\
\hline LYG & 11377 & 2290 & 0 & 987 & 11377 \\
\hline Total costs (million) & & & & & \\
\hline Medical costs & U.S. \$ 1,286.2 & U.S. \$ 1,439.7 & U.S. \$ 1,534.9 & & \\
\hline Vaccine costs & U.S. \$ 103.6 & U.S. \$ 47.6 & - & & U.S. \$ -97.5 \\
\hline Total & U.S. \$ 1,389.8 & U.S. \$ 1,487.3 & U.S. \$ 1,534.9 & & U.S. \$ - 145.1 \\
\hline
\end{tabular}

pneumonia versus no vaccination strategy, unlike PPSV23 that would prevent $26.9 \%$ and $6.2 \%$, respectively (Table 4 ).

In the probabilistic sensitivity analysis, among one thousand simulations of the model, PCV13 had a lower cost than PPSV23 in 100\% of cases, there was more LYG in $64 \%$ of cases and it was cost-effective in $87 \%$ of cases, taking into account a willingness to pay of $3 \mathrm{GPD}$ (U.S. \$ 23,799) [49] (Figure 2).

In the same way, in cost effectiveness plane, PCV13 is dominant over PPSV23 and no vaccination, which is due to be a strategy with greater clinical effectiveness and lower costs (Figure 3).

\section{Discussion}

This cost-effectiveness analysis has identified both clinical and economic outcomes of the alternatives that exist in the Colombian market to prevent pneumococcal diseases in adults over 50 years: PCV13 and PPSV23. From the perspective of a third-party payer, both strategies are dominant versus non-vaccination, in terms of avoided diseases and deaths, ICER, and LYG. In addition, PCV13 was cost-saving, and is below the threshold of 1 per capita gross domestic product Colombian in 2012 (estimated at U.S. \$ 7.933) [49], according to WHO recommendations [50].

Since 2009, several Colombian cities are including PPSV23 within their immunization plan. In 2011, PCV13 received health registration for use in people over 50 years to prevent pneumococcal diseases. Results of this costeffectiveness analysis are intended to generate information to make decisions regarding the choice of two options that are on the market.

The results of this cost-effectiveness analysis are similar to those reported recently by Smith et al. and Weycker

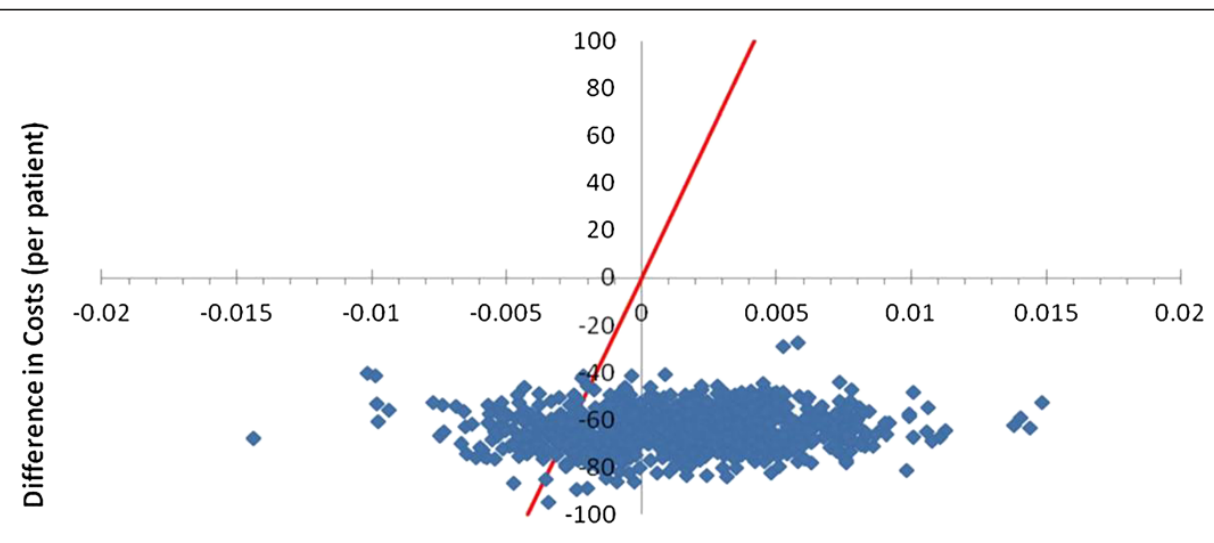

Difference in Life-Years (per patient)

Figure 2 Probabilistic sensitivity analysis, which plotted life years gained versus costs for PCV13 and PPSV23 in a cohort of people over 50 years in Colombia, 2012. 


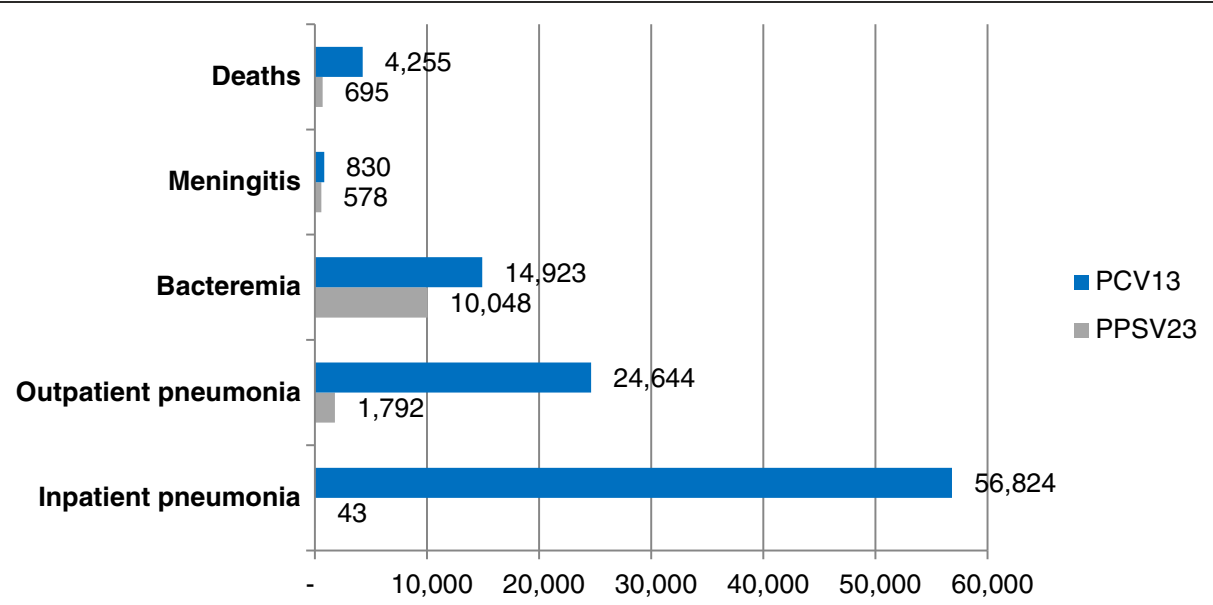

Figure 3 Number of cases avoided with PCV13 and PPSV23 compared to no vaccination in a cohort of people over 50 years in Colombia, 2012.

et al. in the US, both of which concluded that PCV13 in adults over 50 years of age is a better strategy than PPSV23 in terms of cost-effectiveness, to prevent pneumococcal infections in adults in the United States [24,51].

Although this cost-effectiveness analysis only considered the use of one dose of both, PCV13 or PPSV23 because the time horizon was five years, it is important to note that if the time horizon would have been the life expectancy, two doses of PPSV23 should be used for people at high risk, according to its manufacturers.

In the other hand, a meta-analysis published by Moberley et al. recommends PPSV23 versus placebo to prevent pneumococcal diseases [52]. RCTs used in that meta-analysis and published between 1980 and 2006 did not found any evidence about PPSV23 as protective vaccine to avoid pneumonia [40,41,53-58]. It means that the conclusion of Moberley et al. is based on only two RCTs: Kaufman (1948) [13] and Riley (1977) [59]. It is important to note that these RCTs $[13,59]$ did not identified infection by $S$. pneumoniae but Diplococcus pneumoniae, which is a different microorganism.

Clinical effectiveness of pneumococcal conjugate vaccines for IPD in adults is judged by non-inferiority of antibody response compared with PPSV23. Jackson et al. showed that in people aged 70 years and older, opsonophagocytic activity titers were significantly greater in the PCV13 group versus PPSV23 group for 10 of the 12 serotypes common to both vaccines and to serotype $6 \mathrm{~A}$ which is only in PCV13. Responses were non-inferior for the other 2 common serotypes [60]. Much effectiveness, particularly in pneumonia, is inferred based on PCV13 being a conjugated vaccine and eliciting a T-cell dependent response. This is supported by effectiveness in children reducing pneumonia and nasopharyngeal carriage, in fact, Cappuy et al. demonstrated that 2 to 4 years following PCV7 introduction, predominant pneumococcus serotypes carried in children with community-acquired pneumonia were non PCV7 serotypes [61].

A main strength of this study is that it has local information, which helps determine the epidemiological parameters for diseases of interest in Colombia [31]. Also, medical costs of treatments are based on local data [46] and are not supposed on studies done in other countries with different economic realities. In the same way, to adjust efficacy of both vaccines based on pneumococcal serotypes circulating in the country between 2005 and 2010, allows having an updated analysis [21]. So, by having local and updated economic and epidemiological information, we can develop a robust economic model, that allows to national and regional health authorities assess their vaccination plans and take decisions.

The biggest limitation of this study is that there is not effectiveness data for PCV13 in this population. However, the advantages of conjugation are expected to enhance effectiveness against mucosal disease, such as pneumonia, increase immune memory compared to plain polysaccharide vaccine, and improve effectiveness in high risk populations such as immunocompromised. In a study of PCV7 versus placebo in HIV patients, French et al. found a vaccine efficacy of $74 \%$ (95\% CI: $30 \%-90 \%$ ) to prevent pneumococcal diseases [18]. In other study, Klugman et al. found that vaccination with PCV9 reduced the rates of radiologically confirmed pneumonia, and PCV9 also reduced the incidence of vaccine-serotype and antibiotic-resistant IPD among children with and those without HIV infection [37].

Another weakness of this study, is that there is limited information comparing clinical outcomes of PPSV23 and PCV13 in adults to prevent IPD, which are the most lethal diseases caused by pneumococcus. In the same way, by taking data of disease prevalence from an official source, it could be some underreporting, because quality of this 
kind of information depends that medical practitioners use the correct codes to identify diagnosis.

This analysis did not evaluate after-effects of any of the diseases, why not were estimated years of disabilityadjusted life. But it is noteworthy that in terms of prevention of death from all causes, PCV13 was dominant over PPSV23.

\section{Conclusion}

The results of this study indicate that PCV13 and PPSV23 are better alternatives in terms of cost-effectiveness compared with no vaccination. PCV13 is dominant over PPSV23, since PCV13 prevents more deaths by pneumococcal diseases, generates more LYG, and costs are expected to be lower than PPSV23 in adults over 50 years. Implementation of a vaccination program for adults older than 50 years in Colombia with PCV13 would decrease morbidity and mortality by pneumococcal diseases and would be a cost-saving strategy.

\section{Competing interests}

To Sura EPS, a Colombian company health insurance, which provided the data for hospitalization costs

\section{Authors' contributions}

JEO reviewed the scientific literature and identified local epidemiological data. JJO adapted economic model developed by Policy Analysis Inc. Both authors read and approved the final manuscript.

\section{Acknowledgements}

This research was sponsored by Pfizer, Colombia. Researchers declare our full independence of the contractor and we are solely responsible for methods, results and concepts raised in this paper.

\section{Author details}

${ }^{1}$ HEMO Group, Carrera 25 A \# 1 A Sur-45, piso 5. Medellín, Colombia. ${ }^{2}$ CES University, Calle 10 A \# 22-04, Medellín, Colombia.

Received: 24 July 2013 Accepted: 19 March 2014

Published: 28 March 2014

\section{References}

1. Fedson DS, Liss C: Precise answers to the wrong question: prospective clinical trials and the meta-analyses of pneumococcal vaccine in elderly and high-risk adults. Vaccine 2004, 22(8):927-946.

2. WHO: Pneumococcal disease. 2013. [Internet] Available in http://www.who. int/immunization/topics/pneumococcal_disease/en/index.html Accessed February 2013

3. Pallares R, Liñares J, Vadillo M, Cabellos C, Manresa F, Viladrich PF, Martin R, Gudiol F: Resistance to penicillin and cephalosporin and mortality from severe pneumococcal pneumonia in Barcelona. Spain. N Engl J Med 1995, 333(8):474-480.

4. Kalin M, Ortqvist A, Almela M, Aufwerber E, Dwyer R, Henriques B, Jorup C, Julander I, Marrie TJ, Mufson MA, Riquelme R, Thalme A, Torres A, Woodhead MA: Prospective study of prognostic factors in community-acquired bacteremic pneumococcal disease in 5 countries. I Infect Dis 2000, 182(3):840-847.

5. Musher DM, Alexandraki I, Graviss EA, Yanbeiy N, Eid A, Inderias LA, Phan $\mathrm{HM}$, Solomon E: Bacteremic and nonbacteremic pneumococcal pneumonia. A prospective study. Medicine (Baltimore) 2000, 79(4):210-221.

6. Mufson MA, Stanek RJ: Bacteremic pneumococcal pneumonia in one American City: a 20-year longitudinal study, 1978-1997. Am J Med 1999, 107(1A):34S-43S.
7. Robinson KA, Baughman W, Rothrock G, Barrett NL, Pass M, Lexau C, Damaske B, Stefonek K, Barnes B, Patterson J, Zell ER, Schuchat A, Whitney $C G$, Active Bacterial Core Surveillance (ABCs)/Emerging Infections Program Network: Epidemiology of invasive Streptococcus pneumoniae infections in the United States, 1995-1998: Opportunities for prevention in the conjugate vaccine era. JAMA 2001, 285(13):1729-1735.

8. Laurichesse H, Romaszko JP, Nguyen LT, Souweine B, Poirier V, Guólon D, André M, Ruivard M, De Champs C, Caillaud D, Labbé A, Beytout J: Clinical characteristics and outcome of patients with invasive pneumococcal disease, Puy-de-Dôme, France, 1994-1998. Eur J Clin Microbiol Infect Dis 2001, 20(5):299-308

9. WHO: Antimicrobial resistance. 2013. [Internet] Available in http://www who.int/mediacentre/factsheets/fs194/en/ Accessed February 2013.

10. Alonso-Fernández $P$, De la Fuente $M$ : Role of the immune system in aging and longevity. Curr Aging Sci 2011, 4(2):78-100.

11. Snedecor SJ, Strutton DR, Ciuryla V, Schwartz EJ, Botteman MF: Transmission-dynamic model to capture the indirect effects of infant vaccination with Prevnar (7-valent pneumococcal conjugate vaccine (PCV7)) in older populations. Vaccine 2009, 27(34):4694-4703.

12. MacLeod CM, Hodges RG: Prevention of pneumococcal pneumonia by immunization with specific capsular polysaccharides. J Exp Med 1945, 82:445-465

13. Kaufman P: Pneumonia in old age; active immunization against pneumonia with pneumonococcus polysaccharide; results of a six year study. Arch Intern Med (Chic) 1947, 79(5):518-531.

14. World Health Organization: 23-valent pneumococcal polysaccharide vaccine. WHO position paper. Wkly Epidemiol Rec 2008, 42:373-384.

15. Black S, Shinefield H, Fireman B, Lewis E, Ray P, Hansen JR, Elvin L, Ensor KM, Hackell J, Siber G, Malinoski F, Madore D, Chang I, Kohberger R, Watson W, Austrian R, Edwards K: Efficacy, safety and immunogenicity of heptavalent pneumococcal conjugate vaccine in children. Northern California Kaiser Permanente Vaccine Study Center Group. Pediatr Infect Dis J 2000, 19(3):187-195.

16. Black SB, Shinefield HR, Ling S, Hansen J, Fireman B, Spring D, Noyes J, Lewis E, Ray P, Lee J, Hackell J: Effectiveness of heptavalent pneumococcal conjugate vaccine in children younger than five years of age for prevention of pneumonia. Pediatr Infect Dis J 2002, 21(9):810-815.

17. Pavia M, Bianco A, Nobile CGA, Marinelli P, Angelillo IF: Efficacy of pneumococcal vaccination in children younger than 24 months: a meta-analysis. Pediatrics 2009, 123(6):e1103-e1110.

18. French N, Gordon SB, Mwalukomo T, White SA, Mwafulirwa G, Longwe H, Mwaiponya M, Zijlstra EE, Molyneux ME, Gilks CF: A trial of a 7-valent pneumococcal conjugate vaccine in HIV-infected adults. N Engl J Med 2010, 362(9):812-822.

19. SAGE pneumococcal conjugate vaccine working group: Detailed review paper on pneumococcal conjugate vaccine - presented to the WHO Strategic Advisory Group of Experts (SAGE) on immunization; 2013. [Internet] Available in http:// www.who.int/immunization/SAGE_wg_detailedreview_pneumoVaccine.pdf Accessed February 2013.

20. Weycker D, Sato R, Strutton D, Edelsberg J, Atwood M, Jackson LA: Public health and economic impact of 13-valent pneumococcal conjugate vaccine in US adults aged $\geq 50$ years. Vaccine 2012, 30(36):5437-5444.

21. Instituto Nacional de Salud: Aislamientos invasores de Streptococcus pneumoniae, Haemophilus influenzae, Neisseria meningitidis. Colombia. Resultados de la vigilancia por departamentos. SIREVA II 2003-2012. [Internet]. Available in http://www.ins.gov.co/Noticias/SiteAssets/Paginas/SIREVA-II-Colombia2003-2012/SIREVA\%20II\%20Colombia\%202003-2012.pdf Accesed December 2013.

22. Making choices in health: WHO guide to cost-effectiveness analysis; 2013. [Internet]. Available in http://www.who.int/choice/publications/ p_2003_generalised_cea.pdf Accessed February 2013.

23. DANE: Departamento Administrativo Nacional de Estadísticas. Variaciones porcentuales de Indice de Precios al Consumidor (IPC), actualizado a mayo de 2013; 2013. [Internet]. Available in http://www.dane.gov.co/index.php/indices-deprecios-ycostos/indice-de-precios-al-consumidor-ipc Accessed May 2013.

24. Weycker D, Strutton D, Edelsberg J, Sato R, Jackson LA: Clinical and economic burden of pneumococcal disease in older US adults. Vaccine 2010, 28(31):4955-4960.

25. Kyaw MH, Rose CE Jr, Fry AM, Singleton JA, Moore Z, Zell ER, Whitney CG, Active Bacterial Core Surveillance Program of the Emerging Infections Program Network: The influence of chronic illnesses on the incidence of invasive pneumococcal disease in adults. J Infect Dis 2005, 192(3):377-386. 
26. Prevention of Pneumococcal Disease: Recommendations of the Advisory Committee on Immunization Practices (ACIP) 2013; 2013. [Internet]. Available in http://www.cdc.gov/vaccines/schedules/downloads/adult/adult-schedule. pdf Accessed February 2013.

27. Rubin JL, MCGarry L, Strutton DR, Klugman KP, Pelton SI, Gilmore KE, Weinstein MC: Public health and economic impact of the 13-valent pneumococcal conjugate vaccine (PCV13) in the United States. Vaccine 2010, 28(48):7634-7643.

28. Castañeda-Orjuela C, Alvis-Guzmán N, De la Hoz-Restrepo F: [The impact of pneumococcal disease on adults living in Bogota, Colombia, 2008]. Rev Salud Publica (Bogota) 2010, 12(1):38-50.

29. Dickinson FO, Pérez AE: Meningoencefalitis bacteriana en Cuba. Rev Cubana Hig Epidemiol 2001, 39(2):86-94

30. Castañeda-Orjuela C, Alvis-Guzmán N, Paternina AJ, De la Hoz-Restrepo F: Cost-effectiveness of the introduction of the pneumococcal polysaccharide vaccine in elderly Colombian population. Vaccine 2011, 29(44):7644-7650.

31. Departamento Administrativo Nacional de Estadística (DANE): Proyecciones nacionales y departamentales de población 2005-2020. Bogotá DC: DANE; 2010.

32. Koivula I, Stén M, Mäkelä PH: Prognosis after community-acquired pneumonia in the elderly: a population-based 12-year follow-up study. Arch Intern Med 1999, 159(14):1550-1555.

33. Smith KJ, Zimmerman RK, Lin CJ, Nowalk MP, Ko F-S, McEllistrem MC, Roberts MS: Alternative strategies for adult pneumococcal polysaccharide vaccination: a cost-effectiveness analysis. Vaccine 2008, 26(11):1420-1431.

34. Shapiro ED, Berg AT, Austrian R, Schroeder D, Parcells V, Margolis A, Adair RK, Clemens JD: The protective efficacy of polyvalent pneumococcal polysaccharide vaccine. N Engl J Med 1991, 325(21):1453-1460.

35. Impact of the universal pneumococcal immunisation programme for $80+$ year olds in England and Wales using the 23-valent plain pneumococcal polysaccharide vaccine (PPV): January 2005. 2013. [Internet] Available in http://www.hpa.org.uk/webc/HPAwebFile/HPAweb_C/1194947345016 Accesed February 2013

36. Hansen J, Black S, Shinefield H, Cherian T, Benson J, Fireman B, Lewis E, Ray P, Lee J: Effectiveness of heptavalent pneumococcal conjugate vaccine in children younger than 5 years of age for prevention of pneumonia: updated analysis using World Health Organization standardized interpretation of chest radiographs. Pediatr Infect Dis J 2006, 25(9):779-781.

37. Klugman KP, Madhi SA, Huebner RE, Kohberger R, Mbelle N, Pierce N: A trial of a 9-valent pneumococcal conjugate vaccine in children with and those without HIV infection. N Engl J Med 2003, 349(14):1341-1348.

38. Feavers I, Knezevic I, Powell M, Griffiths E: Challenges in the evaluation and licensing of new pneumococcal vaccines, 7-8 July 2008, Ottawa, Canada. Vaccine 2009, 27(28):3681-3688.

39. Jódar L, Butler J, Carlone G, Dagan R, Goldblatt D, Käyhty H, Klugman K, Plikaytis B, Siber G, Kohberger R, Chang I, Cherian T: Serological criteria for evaluation and licensure of new pneumococcal conjugate vaccine formulations for use in infants. Vaccine 2003, 21(23):3265-3272

40. Simberkoff MS, Cross AP, Al-lbrahim M, Baltch AL, Geiseler PJ, Nadler J, Richmond AS, Smith RP, Schiffman G, Shepard DS, Van Eeckhout JP: Efficacy of pneumococcal vaccine in high-risk patients. Results of a Veterans Administration Cooperative Study. N Engl J Med 1986, 315(21):1318-1327.

41. Ortqvist A, Hedlund J, Burman LA, Elbel E, Höfer M, Leinonen M, Lindblad I, Sundelöf B, Kalin M: Randomised trial of 23-valent pneumococcal capsular polysaccharide vaccine in prevention of pneumonia in middle-aged and elderly people. Swedish Pneumococcal Vaccination Study Group. Lancet 1998, 351(9100):399-403.

42. Fry AM, Zell ER, Schuchat A, Butler JC, Whitney CG: Comparing potentia benefits of new pneumococcal vaccines with the current polysaccharide vaccine in the elderly. Vaccine 2002, 21(3-4):303-311.

43. Sisk JE, Whang W, Butler JC, Sneller V-P, Whitney CG: Cost-effectiveness of vaccination against invasive pneumococcal disease among people 50 through 64 years of age: role of comorbid conditions and race. Ann Intern Med 2003, 138(12):960-968.

44. Johnstone J, Marrie TJ, Eurich DT, Majumdar SR: Effect of pneumococcal vaccination in hospitalized adults with community-acquired pneumonia. Arch Intern Med 2007, 167(18):1938-1943.

45. Evers SMAA, Ament AJHA, Colombo GL, Konradsen HB, Reinert RR, Sauerland D, Wittrup-Jensen K, Loiseau C, Fedson DS: Cost-effectiveness of pneumococcal vaccination for prevention of invasive pneumococcal disease in the elderly: an update for 10 Western European countries. Eur J Clin Microbiol Infect Dis 2007, 26(8):531-540.
46. Pan American Health Organization: Expanded Program of Immunization Vaccine Prices for year 2012. 2013. [Internet] Available in www.paho.org Accesed February 2013

47. Banco de la República: Serie empalmada de la tasa de cambio del peso colombiano frente al dólar (TRM y Certificado de cambio). 2013. [Internet] Available in http://www.banrep.gov.co/es/trm Accesed June 2013.

48. Calderón $\mathrm{C}$, Denis R: Costos económicos de neumonía adquirida en comunidad, meningitis y bacteriemia por Streptococcus pneumoniae en una población adulta que requirió hospitalización en Bogotá, Colombia. Biomédica 2014, 34(1):92-101.

49. Banco de la República: PIB total y por habitante. 2013. [Internet] Available in http://banrep.gov.co/es/info-temas-a/4024 Accessed July 2013.

50. WHO: Choosing Interventions that are Cost Effective (WHO-CHOICE). 2013. [Internet] Available in http://www.who.int/choice/en/ Accessed February 2013

51. Smith KJ, Wateska AR, Nowalk MP, Raymund M, Nuorti JP, Zimmerman RK: Cost-effectiveness of adult vaccination strategies using pneumococcal conjugate vaccine compared with pneumococcal polysaccharide vaccine. JAMA 2012, 307(8):804-812.

52. Moberley SA, Holden J, Tatham DP, Andrews RM: Vaccines for preventing pneumococcal infection in adults. Cochrane Database Syst Rev 2008, 1. CD000422.

53. Alfageme I, Vazquez R, Reyes N, Muñoz J, Fernández A, Hernandez M, Merino M, Perez J, Lima J: Clinical efficacy of anti-pneumococcal vaccination in patients with COPD. Thorax 2006, 61(3):189-195.

54. Austrian R: Surveillance of pneumococcal infection for field trials of polyvalent pneumococcal vaccines. Pennsylvania: National Institute of Allergy and Infectious Diseases (U.S.), University of Pennsylvania; 1980.

55. Davis AL, Aranda CP, Schiffman G, Christianson LC: Pneumococcal infection and immunologic response to pneumococcal vaccine in chronic obstructive pulmonary disease. A pilot study. Chest 1987, 92(2):201-212.

56. Gaillat J, Zmirou D, Mallaret MR, Rouhan D, Bru JP, Stahl JP, Delormas P, Micoud M: Clinical trial of an anti-pneumococcal vaccine in elderly people living in institution. Rev Epidemiol Sante Publique 1985, 33:437-444.

57. Klastersky J, Mommen P, Cantraine F, Safary A: Placebo controlled pneumococcal infection in patients with bronchogenic carcinoma. Eur $J$ Cancer Clin Oncol 1986, 22(7):807-813.

58. Leech JA, Gervais A, Ruben FL: Efficacy of pneumococcal vaccine in severe chronic obstructive pulmonary disease. CMAJ 1987, 136(4):361-365.

59. Riley ID, Tarr PI, Andrews M, Pfeiffer M, Howard R, Challands P, Jennison G: Immunisation with a polyvalent pneumococcal vaccine. Reduction of adult respiratory mortality in a New Guinea Highlands community. Lancet 1977, 1(8026):1338-1341.

60. Jackson LA, Gurtman A, Rice K, Pauksens K, Greenberg RN, Jones TR, Scott DA, Emini EA, Gruber WC, Schmoele-Thoma B: Immunogenicity and safety of a 13-valent pneumococcal conjugate vaccine in adults 70 years of age and older previously vaccinated with 23-valent pneumococcal polysaccharide vaccine. Vaccine 2013, 31(35):3585-3593.

61. Chappuy H, Keitel K, Gehri M, Tabin R, Robitaille L, Raymond F, Corbeil J, Maspoli V, Bouazza N, Alcoba G, Lacroix L, Manzano S, Galetto-Lacour A, Gervaix A: Nasopharyngeal carriage of individual Streptococcus pneumonia serotypes during pediatric radiologically confirmed community acquired pneumonia following PCV7 introduction in Switzerland. BMC Infect Dis 2013, 13:357.

doi:10.1186/1471-2334-14-172

Cite this article as: Ordóñez and Orozco: Cost-effectiveness analysis of pneumococcal conjugate vaccine 13-valent in older adults in Colombia. BMC Infectious Diseases 2014 14:172. 